\title{
Nevrografi ved karpaltunnelsyndrom
}

\author{
BAKGRUNN Flere kunnskapsbaserte retningslinjer anbefaler nå at nevrografi benyttes for \\ å bekrefte om det foreligger karpaltunnelsyndrom før en eventuell operasjon.
}

KUNNSKAPSGRUNNLAG Artikkelen er basert på et søk i PubMed, et personlig litteraturarkiv (1980-2011) og lang klinisk erfaring innen nevrologisk og nevrofysiologisk diagnostikk.

RESULTATER Både motoriske og sensoriske nervefascikler må undersøkes etter tilstrekkelig oppvarming. Utvidet nevrografi, med tilleggsundersøkelser der man sammenlikner nerveledningshastighet og latenstid i nervus medianus og nervus ulnaris, øker den diagnostiske presisjonen. Ved normale og lette funn kan operasjon som regel unngås som første behandlingsvalg, fordi mange pasienter med karpaltunnelsyndrom blir spontant bedre.

FORTOLKNING Gullstandard for diagnosen karpaltunnelsyndrom bør være en kombinasjon av klinisk undersøkelse og nevrografi.

Det var et gjennombrudd for diagnostisk klinisk nevrofysiologi da Dawson og Scott i 1949 kunne rapportere vellykket måling av nerveaksjonspotensialer fra elektroder plassert utenpå huden (1). I 1956 kunne Simpson påvise lokal reduksjon av nerveledningshastighet ved karpaltunnelsyndrom (2). Det nevrofysiologiske utstyret gjennomgikk en betydelig teknologisk utvikling de neste tiårene, og måling av nerveledningshastighet (nevrografi) ble raskt - og er fortsatt - den viktigste laboratorieundersøkelsen i diagnostikken av karpaltunnelsyndrom (3).

Selv om nevrografi ble anbefalt og benyttet av de fleste nevrologiske og kirurgiske fagmiljøene ved klinisk mistanke om karpaltunnelsyndrom, har det $\mathrm{i}$ alle år pågått en faglig debatt om det kan være forsvarlig, eller til og med hensiktsmessig, å behandle pasienter for karpaltunnelsyndrom uten forutgående nevrografi.

Vi ønsker i denne artikkelen å beskrive nytteverdien av nevrografi ved denne tilstanden og hvordan metoden har utviklet seg ytterligere de siste to tiår. Vi vil også gjennomgå relevant litteratur som omhandler bruken av nevrografi i diagnostikken av karpaltunnelsyndrom og i utredningen av eventuelle postoperative plager.

\section{Kunnskapsgrunnlag}

Artikkelen er basert på et søk i PubMed avsluttet i februar 2012, der vi i hovedsak har benyttet en kombinasjon av søkeordene «carpal tunnel syndrome» og «nerve conduction». Vi har også brukt kombinasjonen av «carpal tunnel syndrome» og «guideline» og «practice parameter». Artikkelen baserer seg også på personlig litteraturarkiv (1980-2011) og lang erfaring med nevrologisk og nevrofysiologisk diagnostikk.

\section{Symptomer og funn}

Karpaltunnelsyndrom er en vanlig tilstand som skyldes trange forhold i karpaltunnelen i håndleddet (se illustrasjonen). Prevalensen av klinisk betydningsfull sykdom er ca. $2 \%$ for menn og 3-5\% for kvinner (4). Opptil $15 \%$ av befolkningen kan ha symptomer i form av parestesier og nummenhet med nattlig forverring i finger 1-4 (5), og disse sensoriske symptomene forsvinner oftest når pasienten rister eller beveger hånden.

Det er viktig å understreke at parestesier og nummenhet også forekommer ved andre tilstander. Differensialdiagnosene omfatter blant annet cervikal radikulopati, polynevropati, pleksusaffeksjoner, andre mononevropatier, skalenusportavklemming, hyperventilasjon, migrene, transitorisk iskemisk anfall (TIA) og andre sentralnervesykdommer. Det er derfor nyttig å kunne supplere utredningen med nevrografi.

Nevrologiske utfall med thenaratrofi og/ eller nedsatt sensibilitet i innervasjonsområdet for medianusnerven forekommer sjelden. I slike tilfeller er det indikasjon for rask nevrofysiologisk utredning og kirurgisk behandling.

\section{Behandlingsalternativer og komplikasjoner}

Ved lette til moderate symptomer er prognosen god, og 20-48 \% opplever spontan tilbakegang (6). Prognosen er enda bedre etter fødsel når karpaltunnelsyndrom debuterer under graviditet, selv om $30 \%$ kan ha persisterende symptomer tre år etter fødselen (7). Mange pasienter kan derfor behandles konservativt med nattlig håndleddskinne, aktivitetsjustering eller få lokal stereoidinjeksjon (8). Lengden av oppfølgingstiden må bestemmes på individuelt klinisk grunnlag.

Åpen eller endoskopisk kirurgisk frileg-

\section{Kari Todnem}

Avdeling for nevrologi og klinisk nevrofysiologi St. Olavs hospital

\section{Trond Sand}

trond.sand@ntnu.no

Institutt for nevromedisin

Norges teknisk-naturvitenskapelige universitetet og

Avdeling for nevrologi og klinisk nevrofysiologi St. Olavs hospital

\section{HOVEDBUDSKAP}

Nevrografi er en god, pålitelig og som regel nødvendig undersøkelse ved karpaltunnelsyndrom

Standardisert nevrografi, god oppvarming, god opplæring av teknisk personale og utvidet protokoll med tilleggsundersøkelser gir optimal diagnostisk presisjon

Flere kunnskapsbaserte tverrfaglige retningslinjer anbefaler nevrografi før operativ behandling

En kombinasjon av kliniske funn og nevrografi bør være gullstandard for diagnostisering av karpaltunnelsyndrom 

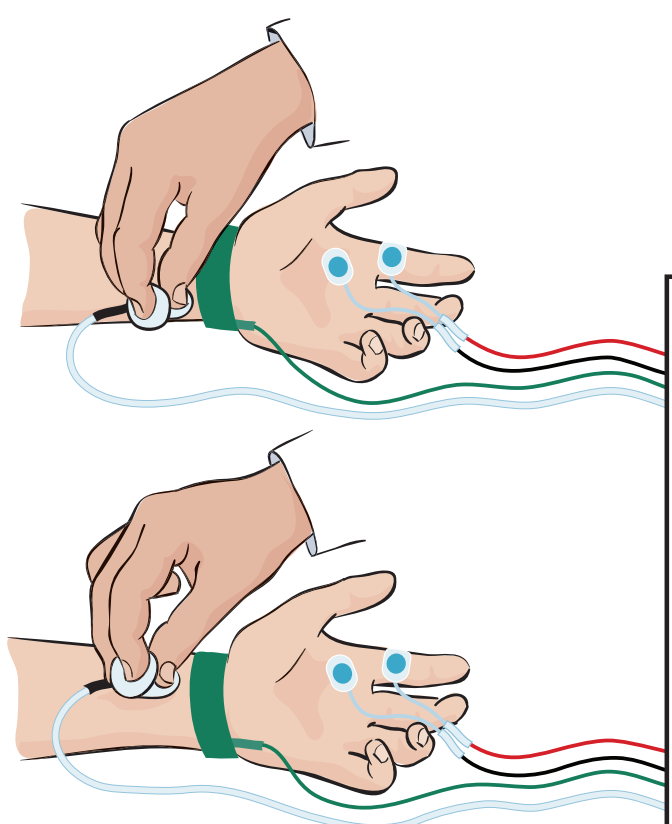

Median-ulnar latenstidsforskjell $=5 \mathrm{~ms}$ (normalt $<0.8 \mathrm{~ms}$ )
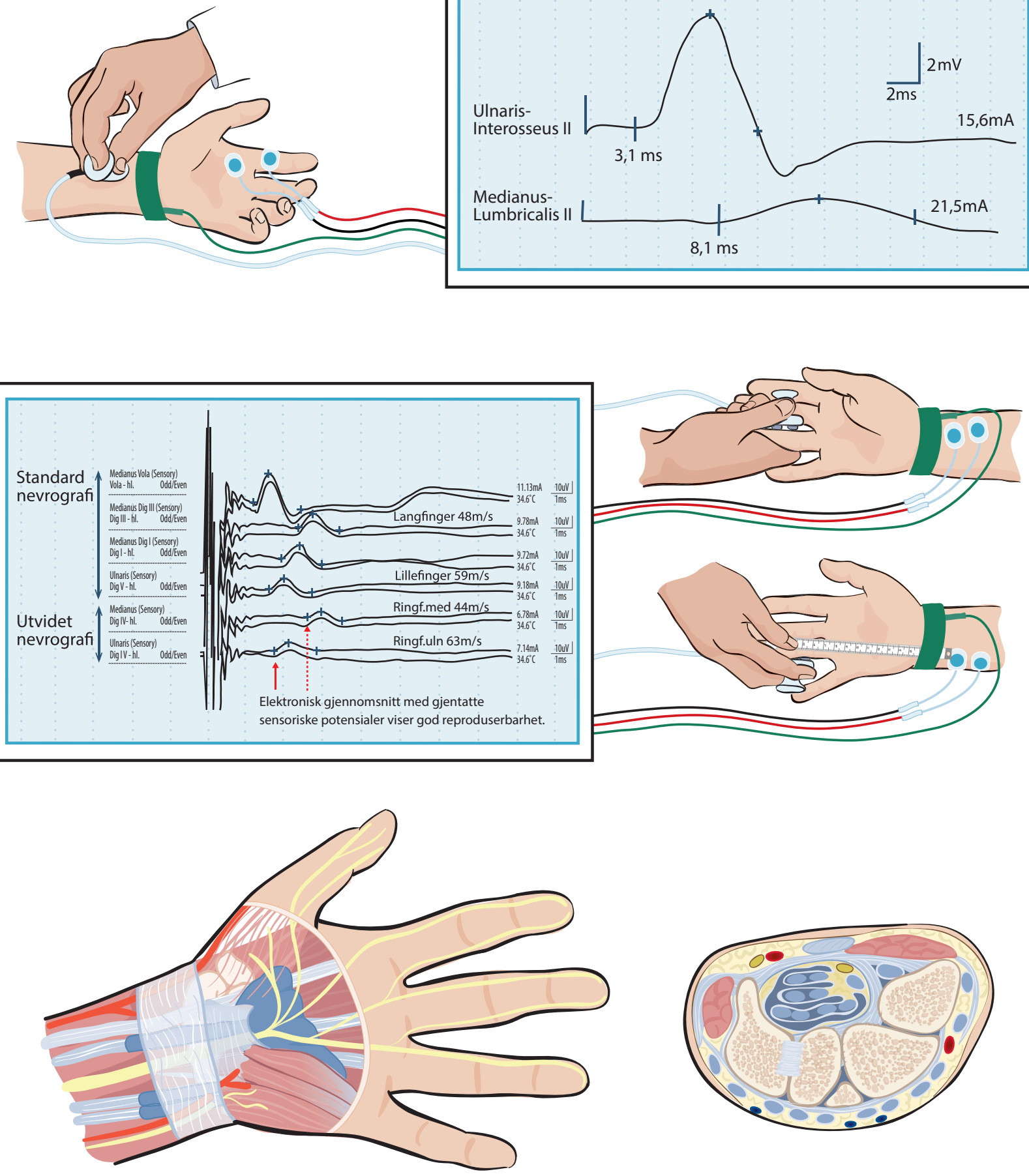

De to øverste figurene viser teknikk for måling av distal motorisk latenstid til m. interosseus II som innerveres av n. ulnaris og m. lumbricalis II som innerveres av n. medianus. Registreringelektrodene har samme posisjon, mens den bipolare sadelstimulatoren flyttes fra ulnaris (øverst) til medianus (nederst). Til høyre for disse vises utskrift av motorisk utvidet nevrografi med uttalt karpaltunnelsyndrom og betydelig forlenget latenstid i medianus til m. lumbricalis II. Stimulusintensitet er angitt i mA. De to neste figurene viser teknikk for måling av sensorisk nerveledningshastighet fra den medianus- (øverst) og ulnarisinnerverte delen (nederst) av ringfingeren. Nøyaktig avstandsmåling til nærmeste millimeter må utføres. Til venstre for disse vises sensorisk nevrografi med normal hastighet $i$. ulnaris og lett redusert hastighet både i nervegrener fra medianusinnervert langfinger og i det volare medianussegmentet mellom håndflate og håndledd. Utvidet nevrografi viser en tydelig forskjell i hastighet mellom den medianus- og ulnarisinnerverte delen av ringfingeren (stiplet og heltrukket vertikal pill. Nederst illustreres hvordan $n$. medianus går gjennom karpaltunnelen i håndleddet sammen med fleksorsenene. Karpaltunnelsyndrom skyldes at det blir for trangt i denne passasjen. Illustrasjon $\odot \mathrm{J}$. Engqvist/lllumedic 


\section{RAMME 1}

Nevrografisk klassifikasjon, modifisert etter Padua og medarbeidere (15)

0 (negativ) Helt normal nevrografi

1 (minimal) Kun unormale segmentale eller sammenliknende tester i utvidet nevrografi

2 (mild) Unormal sensorisk ledningshastighet med normal distal motorisk latens

3 (moderat) Unormal sensorisk ledningshastighet og unormal distal motorisk latens

4 (uttalt) Ingen sikre sensoriske svar og unormal distal motorisk latens

5 (svært uttalt) Ingen sikre sensoriske eller motoriske svar

ging av nerven utført av en erfaren spesialist er allikevel ansett som den beste behandling for karpaltunnelsyndrompasienter med nevrologiske utfall, rask forverring, betydelige plager eller manglende respons på konservativ behandling (9). Det er også vist at eldre (10) og diabetespasienter (11) har god nytte av operasjon.

Selv om peroperative nerveskader og andre komplikasjoner forekommer svært sjelden $(0,5-1 \%)$, kan nevropatisk smerte forringe livskvaliteten i betydelig grad (12). I tillegg vil ca. $25 \%(0-70 \%$ i forskjellige studier) av pasientene føle at operasjonsresultatet ikke var vellykket (13). Operasjon bør derfor i hovedsak tilbys pasienter med både symptomer og unormal nevrografi.

\section{Nevrografimetoden}

God og langvarig oppvarming av hånden og underarmen til $34^{\circ} \mathrm{C}$ med varmelampe eller varmepakninger er helt nødvendig, fordi nerveledningshastigheten reduseres med $1-2 \mathrm{~m} / \mathrm{s}$ per grad (14). Det utføres motorisk og sensorisk nevrografi på alle pasienter. Motoriske medianusfascikler stimuleres med kortvarige strømpulser proksimalt for håndleddet $\mathrm{og}$ ved albuen. Når strømstyrken er 10-40 mA, vil depolarisering i alle motoriske aksoner indusere aksjonspotensialer. Nerveaksjonspotensialene starter like under stimulatoren, ledes ut til endeplaten og induserer muskelaksjonspotensialer med påfølgende kontraksjoner i medianusinnerverte håndmuskler. Distal motorisk latenstid er definert som ledningstid fra stimulus gis til responsen begynner. Ved vår avdeling brukes 4,1 ms som øvre normalgrense for distal motorisk latens til musculus abductor pollicis brevis. Apparatets forsterker registrerer det sammensatte muskelaksjonspotensialet på en skjerm. Motorisk nerveledningshastighet beregnes også. Ved utvidet nevrografi stimuleres både medianusnerven og ulnaris- nerven, slik at vi kan sammenlikne latenstidene fra håndleddet til medianusinnerverte $\mathrm{m}$. lumbricalis II og til ulnarisinnervert $\mathrm{m}$. interosseous dorsalis II (se illustrasjonen). Vår øvre normalgrense for denne forskjellen er 0,8 ms.

Ved sensorisk nevrografi måles det sammensatte nerveaksjonspotensialet med elektroder ved håndleddet. Sensoriske medianusfascikler stimuleres da distalt med ringelektroder på lang- eller pekefinger. Vi benytter elektronisk gjennomsnitt for å kunne måle potensialene, som ofte er svært lavamplitudige og oppsplittede hos pasienter med betydelig nevropati. Vår nedre normalgrense for sensorisk ledningshastighet fra langfinger til håndledd $\mathrm{er} 48 \mathrm{~m} / \mathrm{s}$. Deretter stimuleres en medianusgren som inneholder både sensoriske og motoriske fascikler mellom metakarpalbein 2 og $3 \mathrm{i}$ håndflaten (vola). Ved utvidet sensorisk nevrografi sammenlikner vi også ledningshastighetene i medianusnervegrenene og ulnarisnervegrenene fra ringfingeren (se illustrasjonen). Vår øvre normalgrense for denne forskjellen er $12 \mathrm{~m} / \mathrm{s}$.

Det utføres rutinemessig nevrografi av minst én annen nerve for å utelukke ulnarisinnklemming og polynevropati. Pasienter med komplisert sykehistorie kan i tillegg undersøkes med elektromyografi for å vurdere andre differensialdiagnoser.

\section{Tolking og nytteverdi av nevrografi}

Et unormalt nevrografiresultat bør graderes, og et eksempel basert på en italiensk klassifikasjon (15) er vist i ramme 1. En studie basert på dette italienske klassifikasjonssystemet viste uttalte eller svært uttalte funn i $18 \%$ av de undersøkte hendene, lette til moderate forandringer i nerveledningshastighet i $59 \%$ og minimale endringer i $20 \%$ (15). En klinisk diagnose kan bekreftes ved hjelp av nevrografi med en sensitivitet på mer enn $85 \%$ og en spesifisitet på $90-97 \%(16,17)$. Vi anbefaler å benytte utvidede undersøkelser, enten slik som de er beskrevet her eller som angitt i nordamerikanske fagmedisinske anbefalinger (16).

Uttalt motorisk amplitudereduksjon sammen med muskelatrofi forekommer sjelden og som regel sent i forløpet av karpaltunnelsyndrom (15). Sensorisk amplitudereduksjon forårsakes ikke nødvendigvis av aksontap, men kan skyldes blokkering av impulstrafikken i raskt ledende aksoner forårsaket av demyelinisering. Prognosen vil da være bedre enn ved aksonal degenerasjon (9). Uttalt amplitudereduksjon er indikasjon for kirurgisk intervensjon $(18,19)$.

Mange studier viser at postoperativt resultat er bedre hos pasienter med patologisk nevrografi $(20-22)$. I en oversiktsartikkel der man konkluderer med manglende sammenheng mellom godt operasjonsresultat og nevrografi, anføres i sammendraget at datagrunnlaget kun besto av artikler med klare metodiske svakheter (23). Eksempler på slike svakheter er manglende oppvarming (24), uklar definisjon av et vellykket resultat ved oppfølging og manglende blinding av resultatvurderingen (25) eller mangelfull nevrografiprosedyre (26). På grunn av høy spontan remisjonsrate og lav spesifisitet for symptomer som parestesier og nummenhet, kan man ikke bruke et vellykket resultat etter kirurgi som en sikker diagnostisk bekreftelse.

Dersom det oppstår postoperative komplikasjoner, forsinket nervetilheling grunnet preoperativ aksonal nervelesjon, forsinket sårtilheling eller residiv, er det av verdi å ha dokumentert graden av medianusdysfunksjon før operasjonen. Uten preoperativ nevrografi er vår erfaring at det er vanskelig eller umulig å si om funn ved postoperativ nevrografi skyldes preoperativ lesjon, perioperativ skade eller residiv.

\section{Preoperative diagnostiske kriterier}

Hos et flertall av pasienter med karpaltunnelsyndrom er det et godt samsvar mellom kliniske opplysninger og nevrografi (16). Både nevrografi og klinisk utredning kan gi verdifull informasjon om årsak, og de fleste fagmiljøer understreker derfor at diagnosen bør baseres på en kombinasjon av klinisk og nevrografisk undersøkelse. Allerede i 1998 uttalte en konsensusgruppe at denne kombinasjonen gir mest pålitelig informasjon om tilstanden (27). Tyske nevrologer, nevrokirurger, plastikkirurger og håndkirurger uttaler også i sine felles retningslinjer fra 2007 at nevrografi er særlig viktig i diagnostikken (28). I tillegg har den amerikanske ortopedforeningen nylig fastslått at nevrografi bør utføres før operativ behandling (3). Tilsvarende anbefalinger er gitt i Nederland (29) og Norge (30).

\section{Forbedring av diagnostikken}

Bildedannende metoder utvikles stadig og vil etter hvert gi enda bedre supplerende informasjon om anatomiske anomalier som forårsaker noen fokale nevropatier. Den moderate spesifisiteten for konvensjonell MR $(<39 \%)$ i forhold til nevrografi (90-97\%) $(16,17)$ kan sikkert forbedres i fremtiden, men MR er fortsatt mer kostbar enn nevrografi. Det er også en høy korrelasjon mellom nevrografi og ultralydbestemt tverrsnittsareal av medianus $\mathrm{i}$ håndleddet, men nevrografi er mer sensitiv enn ultralyd (31). I tillegg er det uløste problemer vedrørende normalverdier og reproduserbarhet for ultralydbasert nervediagnostikk $(32,33)$.

Vi forventer at nevrografi vil bevare sin plass som den eneste metoden for direkte innsyn både til medianusnervens myeliniseringsgrad og til nerveaksjonspotensialenes funksjon. Metoden er reliabel, med lite avvik i normalverdier mellom laboratorier i forskjellige land (16). Detaljer ved metoden, som grad og varighet av oppvarming og prosedyre for avstandsmåling, kan være vanskelig å standardisere fullstendig. Vi anbefaler derfor at alle klinisk nevrofysiologilaboratorier også kvalitetssikrer sin virksomhet med et eget referansemateriale. 
Ved å anvende gradering av nevrografisvarene mer rutinemessig (15) (ramme 1) kan vi sannsynligvis forbedre opplevd kvalitet hos behandlende lege. Også den kliniske vurderingen kan raffineres ved bruk av skalering (34). Fordi «gullstandard» for diagnostikk av karpaltunnelsyndrom er en kombinasjon av kliniske funn og nevrografi, bør det også utvikles en kombinert klinisknevrografisk skala.

\section{Konklusjon}

Gullstandard for diagnostikk av karpaltunellsyndrom er ikke basert på én dimensjon, men bør defineres som en kombinasjon av klinisk undersøkelse og nevrografi. Et normalt nevrografisvar gir også viktig informasjon, fordi mange kan unngå operasjon og bli spontant bra. Vi anbefaler derfor at nevrografi som en hovedregel utføres hos alle pasienter som har betydelige plager og klinisk mistanke om karpaltunellsyndrom før man beslutter om en planlagt operativ behandling skal gjennomføres.

Pasienter uten nevrologiske utfall som har lette symptomer uten søvnforstyrrende smerter, kortvarige symptomer (mindre enn ca. 3-6 uker), eller har en spesifikk årsak (arbeidsbelastning, tendinitt eller graviditet) kan behandles konservativt i ca. 6-18 uker før man eventuelt henviser til nevrografi $(13,35)$. Variasjonen mellom pasienter er imidlertid stor, og så vidt vi vet er det ingen kunnskapsbaserte retningslinjer for konservativ behandlingslengde som kan erstatte klinisk oppfølging og vurdering av hver enkelt pasient. Ved klinisk forverring under konservativ behandling bør man vurdere raskere henvisning.

Vi forventer et økende behov for nevrografi, også ved mindre sykehus, i alle helseregioner fordi befolkningen blir eldre og fordi forekomsten av diabetes med komplikasjoner vil øke (36). Utdanning av flere spesialister, opplæring av nevrofysiologiingeniører og telemedisinske løsninger er noen tiltak som kan bidra til at alle pasienter i Norge får lik og tilfredsstillende tilgang på klinisk nevrofysiologisk diagnostikk.

\section{Kari Todnem (f. 1944)}

er dr.med., spesialist i klinisk nevrofysiologi og nevrologi og overlege ved Seksjon for nevrofysiologi.

Forfatter har fylt ut ICMJE-skjemaet og oppgir ingen interessekonflikter.

\section{Trond Sand (f. 1952)}

er spesialist i klinisk nevrofysiologi og nevrologi, seksjonsoverlege ved Seksjon for nevrofysiologi og professor i klinisk nevrofysiologi. Forfatter har fylt ut ICMJE-skjemaet og oppgir ingen interessekonflikter.

\section{Litteratur}

1. Dawson GD, Scott JW. The recording of nerve action potentials through skin in man. J Neurol Neurosurg Psychiatry 1949; 12: 259-67.

2. Simpson JA. Electrical signs in the diagnosis of carpal tunnel and related syndromes. J Neurol Neurosurg Psychiatry 1956; 19: 275-80

3. Keith MW, Masear V, Chung KC et al. American Academy of Orthopaedic Surgeons Clinical Practice Guideline on diagnosis of carpal tunnel syndrome. J Bone Joint Surg Am 2009: 91: 2478-9.

4. Atroshi I, Gummesson C, Johnsson R et al. Prevalence of carpal tunnel syndrome in a general population. JAMA 1999; 282: 153-8

5. de Krom MC Knipschild PG, Kester AD et al. Carpal tunnel syndrome: prevalence in the general population. J Clin Epidemiol 1992; 45: 373-6.

6. Ortiz-Corredor F, Enríquez F, Díaz-Ruíz J et al. Natural evolution of carpal tunnel syndrome in untreated patients. Clin Neurophysiol 2008; 119 : $1373-8$.

7. Padua L, Di Pasquale A, Pazzaglia C et al. Systematic review of pregnancy-related carpal tunnel syndrome. Muscle Nerve 2010; 42: 697-702

8. Katz JN, Simmons BP. Clinical practice. Carpal tunnel syndrome. N Engl J Med 2002; 346: $1807-12$.

9. Jarvik JG, Comstock BA, Kliot M et al. Surgery versus non-surgical therapy for carpal tunnel syndrome: a randomised parallel-group trial. Lancet 2009; 374: 1074-81

10. Todnem K, Lundemo G. Median nerve recovery in carpal tunnel syndrome. Muscle Nerve 2000; 23 . $1555-60$

11. Thomsen NO, Rosén I, Dahlin LB. Neurophysiologic recovery after carpal tunnel release in diabetic patients. Clin Neurophysiol 2010; 121: 1569-73.

12. Braun RM, Rechnic M. Fowler E. Complications related to carpal tunnel release. Hand Clin 2002; 18: $347-57$

13. Bland JD. Treatment of carpal tunnel syndrome Muscle Nerve 2007; 36: 167-71.

14. Norsk forening for klinisk nevrofysiologi. Nevrografi. I: Sand T, red. Retningslinjer for metoder i klinisk nevrofysiologi. Del 1. Skriftserie for leger (utdanning og kvalitetssikring). Oslo: Den norske legeforening, 2008: 55-90.

15. Padua L, LoMonaco M, Gregori B et al. Neurophysiological classification and sensitivity in 500 carpal tunnel syndrome hands. Acta Neurol Scand 1997; $96: 211-7$

16. Jablecki CK, Andary MT, Floeter MK et al. Practice parameter: Electrodiagnostic studies in carpal tunnel syndrome. Report of the American Association of Electrodiagnostic Medicine, American Academy of Neurology, and the American Academy of Physical Medicine and Rehabilitation. Neurology 2002; 58: 1589-92.

17. Fleckenstein JL, Wolfe GI. MRI vs EMG: which has the upper hand in carpal tunnel syndrome? Neurology 2002; 58: 1583-4.

18. Finestone HM, Woodbury GM, Collavini T et al. Severe carpal tunnel syndrome: clinical and electrodiagnostic outcome of surgical and conservative treatment. Muscle Nerve 1996; 19: 237-9.

19. Capasso M, Manzoli C, Uncini A. Management of extreme carpal tunnel syndrome: evidence from a long-term follow-up study. Muscle Nerve 2009; 40: $86-93$

20. Dennerlein JT, Soumekh FS, Fossel AH et al. Longer distal motor latency predicts better outcomes of carpal tunnel release. J Occup Environ Med 2002; 44: 176-83

21. Higgs PE, Edwards DF, Martin DS et al. Relation of preoperative nerve-conduction values to outcome in workers with surgically treated carpal tunnel syndrome. J Hand Surg Am 1997; 22: 216-21.

22. Bland JD. Do nerve conduction studies predict the outcome of carpal tunnel decompression? Muscle Nerve 2001; 24: 935-40

23. Jordan R, Carter T, Cummins C. A systematic review of the utility of electrodiagnostic testing in carpal tunnel syndrome. Br J Gen Pract 2002; 52: $670-3$

24. Lama M. Carpal tunnel release in patients with negative neurophysiological examinations: clinical and surgical findings. Neurosurgery 2009; 65 (suppl): A171-3.

25. Finsen V, Russwurm H. Neurophysiology not required before surgery for typical carpal tunnel syndrome. J Hand Surg [Br] 2001; 26: 61-4.

26. Graham B. The value added by electrodiagnostic testing in the diagnosis of carpal tunnel syndrome. J Bone Joint Surg Am 2008; 90: 2587-93.

27. Rempel D, Evanoff B, Amadio PC et al. Consensus criteria for the classification of carpal tunnel syndrome in epidemiologic studies. Am J Public Health 1998; 88: 1447-51.

28. Assmus H, Antoniadis G, Bischoff C et al. Diagnostik und Therapie des Karpaltunnelsyndroms Leitlinie der Deutschen Gesellschaften für Handchirurgie, Neurochirurgie, Neurologie, Orthopädie unter Mitbeteiligung der Gesellschaften für Unfallchirurgie, Klinische Neurophysiologie und Funktionelle Bildgebung sowie Plastiche, Rekonstruktive und Asthetische Chirurgie. Handchir Mikrochir Plast Chir 2007; 39: 276-88.

29. de Krom MC, van Croonenborg JJ, Blaauw G et al. Guideline 'Diagnosis and treatment of carpal tunnel syndrome'. Ned Tijdschr Geneeskd 2008, 152: $76-81$

30. Dietrichs E, Sand T. Karpaltunnelsyndrom. Norsk elektronisk legehåndbok (NEL) http://legehandboka.no/nevrologi/ tilstander-og-sykdommer/nevropatier/ karpaltunnelsyndrom-2478.html (19.1.2012).

31. Padua L, Pazzaglia C, Caliandro P et al. Carpal tunnel syndrome: ultrasound, neurophysiology, clinical and patient-oriented assessment. Clin Neurophysiol 2008; 119: 2064-9.

32. Boon AJ, Harper CM. Ultrasound in the diagnosis of mononeuropathy: future directions. Muscle Nerve 2011: 44: 851-3.

33. Maertens de Noordhout A. Diagnosing entrapment neuropathies: probes and magnets instead of electrodes and needles? Clin Neurophysiol 2006; 117: $484-5$

34. Giannini F, Cioni R, Mondelli M et al. A new clinical scale of carpal tunnel syndrome: validation of the measurement and clinical-neurophysiological assessment. Clin Neurophysiol 2002; 113: 71-7.

35. Shi Q, MacDermid JC. Is surgical intervention more effective than non-surgical treatment for carpal tunnel syndrome? A systematic review. J Orthop Surg 2011; 6: 17

36. Strategisk plan for klinisk nevrofysiologi (KNF) i Norge. http://legeforeningen.no/Fagmed/ Norsk-forening-for-klinisk-nevrofysiologi/ metoder-prosedyrer/ (29.11.2011).

Mottatt 25.1. 2012, første revisjon innsendt 30.4 2012, godkjent 9.9. 2012. Medisinsk redaktør Merete Kile Holtermann. 